\title{
Predictors of the Use of Specific Critical Care Therapies in Patients With Metastatic Cancer
}

\author{
Kah Poh Loh, BMedSci, MBBCh BAOª; Ankit Kansagra, MD ${ }^{\mathrm{b}}$; Meng-Shiou Shieh, PhD; \\ Penelope Pekow, PhD ${ }^{\mathrm{d}, \mathrm{e}}$; Peter Lindenauer, MD, MSc ${ }^{\mathrm{c}, \mathrm{d}}$; Mihaela Stefan, MD, PhD ${ }^{\mathrm{c}, \mathrm{d}}$; and Tara Lagu, MD, MPH ${ }^{\mathrm{c}, \mathrm{d}}$
}

\begin{abstract}
Objective: Understanding which factors are associated with the use of critical care therapies (CCTs) can help with clinical decision-making and goals of care discussion. The goal of this study was to describe the predictors of CCT use (eg, mechanical ventilation, tracheostomy, percutaneous endoscopic gastrostomy tube, total parenteral nutrition, acute use of dialysis) in hospitalized patients with metastatic cancer. Methods: We used the 2010 California State Inpatient Databases sponsored by the Agency for Healthcare Research and Quality to identify all hospitalizations with a diagnosis of metastatic cancer (patients aged $\geq 18$ years). We examined the predictors of any CCT use (and invasive mechanical ventilation [IMV] use), stratified by do-not-resuscitate (DNR) status, using multivariable logistic regression models. Results: We identified 99,085 hospitalizations involving patients with metastatic cancer; $9.4 \%$ received any CCTs and $4.7 \%$ received IMV. Predictors of CCT use in the no-DNR group included principal diagnosis of infections (vs cancer-related), greater burden of comorbidities, and presence of weight loss. Predictors of CCT use in the DNR group were similar, but also included non-white races. Liver disease was also a predictor of IMV use in the no-DNR group. Patients with metastatic lung cancer (vs breast and genitourinary) with no DNR were more likely to receive CCT (and IMV). Conclusions: Higher burden of comorbidities, weight loss, liver disease, lung cancer subtype, and diagnosis of infections were associated with higher odds of receiving CCTs or IMV. These findings may help clinicians determine in whom to prioritize discussions around goals of care, especially in the group without a DNR status.
\end{abstract}

J Natl Compr Canc Netw 2017:15(1):22-30

\section{Introduction}

Spending for cancer care in United States exceeds $\$ 125$ billion annually, ${ }^{1}$ with the highest costs seen among patients with advanced cancer, a stage at which the disease generally is not amenable to curative treatments. ${ }^{2}$ Hospitalization secondary to complications related to cancer and cancer treatments represents one area of high spending, with the highest costs arising from aggressive care at the end of life. ${ }^{3-5}$ Advances in the supportive management of patients with cancer undergoing treatment have led to significant improvements in survival among those requiring hospitalization.

Several existing models have been developed to identify patients who are at risk of chemotherapyrelated hospitalization or emergency department vis-

From aDivision of Hematology/Oncology, James P. Wilmot Cancer Institute, University of Rochester/Strong Memorial Hospital, Rochester, New York;

bDivision of Hematology/Oncology, Department of Medicine, Baystate

Medical Center, Springfield, Massachusetts; 'Department of Medicine,

Tufts University School of Medicine, Springfield, Massachusetts; ${ }^{d}$ Center

for Quality of Care Research, Baystate Medical Center, Springfield,

Massachusetts; and ${ }^{\mathrm{D} D e p a r t m e n t}$ of Biostatistics and Epidemiology,

University of Massachusetts, Amherst, Massachusetts. its. ${ }^{6,7}$ These models can identify high-risk patients who can be targeted with strategies such as early discussion of advanced directive and palliative care evaluation and end-of-life planning. ${ }^{8,9}$ However, there is still a large proportion of patients with metastatic cancer who are hospitalized, especially those on systemic chemotherapy with a reported hospitalization rate as high as $92 \%$. $^{3,10,11}$ Many of these patients will receive invasive critical care therapies (CCTs) during their hospitalization., ${ }^{4,12}$ Given the high risk of mortality among those receiving CCTs, understanding which factors are associated with the use of these therapies could help clinicians prepare patients and families for the possibility of bad outcomes during hospitalization. This knowledge would also encourage clinicians to develop strategies to avoid CCT use in patients unlikely to benefit, including addressing goals of 
care early in the hospitalization for patients at the highest risk.

Using a large state inpatient database, we aimed to describe the predictors of CCT use (eg, mechanical ventilation, tracheostomy, percutaneous endoscopic gastrostomy [PEG] tube, total parenteral nutrition [TPN], acute use of dialysis) in hospitalized patients with metastatic cancer.

\section{Methods}

\section{Design, Setting, and Subjects}

We used the California State Inpatient Databases (CA SID) sponsored by the Agency for Healthcare Research and Quality (AHRQ). The CA SID contains administrative claims data from all California hospital discharges. We chose the CA SID because it is the largest state inpatient database that includes information on do-not-resuscitate (DNR) status. We conducted a crosssectional study and identified all hospitalizations with a diagnosis of metastatic cancer among patients aged $\geq 18$ years between January 1 to December 31, 2010.

Metastatic cancer was defined using ICD-9-CM diagnostic codes (see supplemental eAppendix 1, available with this article at JNCCN.org). ${ }^{13-16}$ Only patients with diagnoses of solid tumors were included in this study because some advanced hematologic malignancies may still be cured.

\section{Patient and Hospital Characteristics}

We collected patient demographics (age, sex, race), payer, admission status (nonelective vs elective), comorbidities, DNR status, cancer subtype, discharge ICD-9-CM code, and hospital characteristics. For analysis, we grouped age into quartiles: age $<55$ years, 55 to 64 years, 65 to 74 years, and $\geq 75$ years. We defined a modified combined comorbidity score derived from the Elixhauser and Charlson comorbidity index to evaluate comorbidities. ${ }^{17}$ Metastatic cancer, weight loss, any tumor, and HIV/AIDS were excluded from this score to avoid redundancy with inclusion criteria. ${ }^{17}$ Analyses included additional individual comorbidities that might impact prognosis in metastatic cancer, such as end-stage renal disease (ESRD; ICD9-CM codes 549.8 and 399.5, excluding acute kidney injury [AKI] codes 584.5-585.9), weight loss, and liver disease. In the CA SID, patients were considered DNR if the order was written at the time of or within first 24 hours of hospital admission. ${ }^{18,19}$
We grouped primary cancer type into lung, breast, genitourinary (GU), colorectal (CRC), other/multiple, or unidentified using ICD-9-CM codes (see supplemental eAppendix 2). ${ }^{13}$ We classified the principal discharge diagnosis for the hospitalization using AHRQ's Clinical Classification Software. ${ }^{20}$

We used the American Hospital Association Annual Survey database to obtain hospital characteristics, which contains responses from 6,300 hospitals nationwide, and information on institutions organizational structure, facility and service lines, inpatient and outpatient care utilization, expenses, and staffing. ${ }^{21}$ The following hospital characteristics were included: teaching status, location (rural or urban), and bed size (small: <200; medium: 200-399; large: $\geq 400$ ).

\section{Outcomes}

The primary outcome was the use of any CCT. Receipt of CCTs was based on the following ICD-9-CM diagnostic and procedure codes: invasive mechanical ventilation (IMV): 96.70-96.72; PEG tube: 43.11; AKI requiring dialysis, requiring both 584.5-585.9 and 39.95; TPN, 99.15; and tracheostomy, 31.1, 31.21, and 31.29. In addition, we also separately evaluated receipt of IMV.

Secondary outcomes included in-hospital mortality, hospital length of stay, cost of care, and discharge disposition for patients. Because the CA SID contains hospital charges calculated by hospital accounting systems, we used Healthcare Cost and Utilization Project hospital-specific cost-to-charge ratios to convert charges to costs. ${ }^{22}$

\section{Analyses}

We compared the characteristics and outcomes of patients who received any CCT versus those did not. We used counts and percentages, means and standard deviations (SD), and percentile distributions to describe patient characteristics. We compared patients who received CCTs and those did not using chi-square tests for categorical variables and Wilcoxon rank-sum tests for continuous variables.

To examine predictors of any CCT use (including IMV, PEG, AKI requiring dialysis, TPN, and tracheostomy), we used multivariable logistic regression with generalized estimating equations to account for hospital clustering. Before creating the models, we tested variables for evidence of interaction. We found that there was a statistically significant interaction 
Loh et al

between DNR status and several variables, including age, race, and cancer type. We therefore opted to stratify the models by DNR status to account for this effect modification. All available patient characteristics were included in the model. Because IMV is associated with the highest mortality compared with some of the other CCTs, we also created models examining only IMV use ( \pm other CCTs), again stratified by DNR status. All analyses were carried out using SAS 9.3 (SAS Institute Inc., Cary, NC). The Baystate Medical Center IRB determined that the project did not constitute human subjects research.

\section{Results}

Demographics, Clinical, and Hospital Characteristics For 2010, we identified 99,085 admissions among patients with metastatic cancer at 318 hospitals. The mean age of the patients was 64.6 years (SD, $14.6)$ and $46 \%$ were male. Most (61\%) were white and $51 \%$ had Medicare listed as their primary insurance. DNR within 24 hours of admission was documented in $16 \%$ of the admissions. Most principal diagnoses were cancer-related (51\%) followed by infections (11\%). The average modified comorbidity score was low (1; SD, 1.8). For cancer subtype, 15\% of cancers originated in the lung, $9 \%$ originated in the breast, and $10 \%$ were classified as CRC and 10\% as GU cancer; $76 \%$ of admissions were nonelective. Half of the patients were seen at teaching hospitals and $30 \%$ were seen at hospitals that had $\geq 400$ beds. Characteristics of the patients who received CCTs and those who did not are shown in Table 1.

\section{Outcomes}

Of the 99,085 admissions with metastatic cancer, $4.7 \%$ received IMV, $3.7 \%$ received TPN, $1.4 \%$ received PEG, $0.7 \%$ received tracheostomy, and $0.7 \%$ had AKI requiring dialysis. Nearly $10 \%$ of patients received $\geq 1$ CCT $(1.5 \%$ received $\geq 2$, and $0.3 \%$ received $\geq 3$ CCTs). In-hospital mortality was $10 \%$ among all admissions, whereas in-hospital mortality among patients who received CCTs was 33\%. Mean hospital length of stay was 6.8 days $(\mathrm{SD}, 9.2)$ for all patients and 14.8 days $(\mathrm{SD}, 15.6)$ for those who received CCTs. Median cost of admission was $\$ 12,858$ for all patients (interquartile range [IQR], \$7,071$\$ 23,842$ ) and $\$ 35,422$ (IQR, $\$ 18,978-\$ 63,403$ ) for patients who received CCTs. Among those who sur- vived the hospitalization, $15 \%$ were discharged to skilled-nursing or intermediate-care facilities (Table 2). Outcomes in patients who received CCTs versus those who did not are shown in Table 2.

\section{Multivariable Analyses}

When we stratified by DNR status, we observed that $9.6 \%$ of patients $(8,000 / 83,708)$ who were not DNR received CCTs, and $4.6 \%(3,879 / 83,708)$ received IMV. Interestingly, among patients who were DNR at admission, the rates of CCT use were slightly lower, but IMV use was similar $(8.8 \%$ [1,346/15,369] received CCTs; 4.8\% [735/15,369] received IMV). We found that significant predictors for use of CCTs in the group without DNR orders included age between 55 and 74 years ( $55-64$ vs < 55 years: odds ratio [OR], 1.09; 95\% CI, 1.02-1.17; and 65-74 vs $<55$ years: OR, 1.12 ; 95\% CI, 1.02-1.22), private insurance versus Medicare (OR, 1.14; 95\% CI, 1.051.23), higher burden of comorbidities (comorbid score $\geq 2$ vs $\leq 0: 2.51 ; 95 \% \mathrm{CI}, 2.36-2.67$ ), and presence of weight loss (OR, 3.23; 95\% CI, 3.04-3.42; Table 3). In contrast, patients with ESRD (OR, 0.55; 95\% CI, 0.41-0.68) were less likely to receive CCTs. Compared with patients with lung cancer, those with CRC (OR, 1.67; 95\% CI, 1.51-1.83) were more likely to receive CCTs, whereas patients with GU cancer (OR, 0.89; 95\% CI, 0.79-0.99) and breast cancer (OR, 0.71; 95\% CI, 0.62-0.80) were less likely to receive CCTs. Administration of CCTs was more common in admissions with a principal diagnosis related to infectious causes along with other pulmonary and gastrointestinal disorders compared with a principal diagnosis of cancer-related causes.

Predictors for CCT use in admissions with DNR orders were similar, except that we saw a very clear trend in decreasing use of CCTs among older patients. Patients aged $\geq 75$ years and who had a DNR status were much less likely to receive CCTs than those aged $<55$ years (OR, 0.62; 95\% CI, 0.48-0.76). Black patients and those of "other" race in the DNR group were also more likely to receive CCTs. Among patients who were DNR, the odds of patients with breast or GU cancers receiving CCTs were not significantly different from those with lung cancer (whereas patients with GU and breast cancer who were not DNR were less likely to receive CCTs than patients with lung cancer), but patients with CRC were still more likely to receive CCTs than those 
Critical Care Therapies in Cancer

\begin{tabular}{|c|c|c|c|c|}
\hline Characteristics & $\begin{array}{l}\text { All Admissions } \\
\quad(n=99,085)\end{array}$ & $\begin{array}{c}\text { Received CCTs } \\
\quad(n=9,348)\end{array}$ & $\begin{array}{l}\text { Did Not Receive } \\
\text { CCTs }(n=89,737)\end{array}$ & $P$ Value \\
\hline Age, mean (SD), y & $64.6(14.6)$ & $65.1(13.8)$ & $64.5(14.7)$ & .0177 \\
\hline \multicolumn{5}{|l|}{ Age, y (\%) } \\
\hline$<55$ & $23,371(23.6)$ & $1,979(21.2)$ & $21,392(23.8)$ & $<.0001$ \\
\hline $55-64$ & $23,875(24.1)$ & $2,319(24.8)$ & $21,556(24.0)$ & \\
\hline $65-74$ & $24,653(24.9)$ & $2,539(27.2)$ & $22,114(24.6)$ & \\
\hline$\geq 75$ & $27,186(27.4)$ & $2,511(26.9)$ & $24,675(27.5)$ & \\
\hline \multicolumn{5}{|l|}{$\operatorname{Sex}^{a}(\%)$} \\
\hline Male & $45,716(46.3)$ & $4,594(49.2)$ & $41,122(46.0)$ & $<.0001$ \\
\hline \multicolumn{5}{|l|}{$\operatorname{Race}^{b}(\%)$} \\
\hline White & $58,285(60.8)$ & $5,272(58.9)$ & $53,013(61.0)$ & $<.0001$ \\
\hline Black & $8,011(8.4)$ & $905(10.1)$ & $7,106(8.2)$ & \\
\hline Hispanic & $17,614(18.4)$ & $1,588(17.7)$ & $16,026(18.4)$ & \\
\hline Other & $11,901(12.4)$ & $1,189(13.3)$ & $10,712(12.3)$ & \\
\hline \multicolumn{5}{|l|}{ Payerc $(\%) w$} \\
\hline Medicare & $50,512(51.0)$ & $4,901(52.4)$ & $45,611(50.8)$ & .0241 \\
\hline Medicaid & $15,111(15.3)$ & $1,407(15.1)$ & $13,704(15.3)$ & \\
\hline Private insurance & $29,986(30.3)$ & $2,732(29.2)$ & $27,254(30.4)$ & \\
\hline No charge/other & $1,396(1.4)$ & $135(1.4)$ & $1,261(1.4)$ & \\
\hline Self-pay & $2,076(2.1)$ & $173(1.9)$ & $1,903(2.1)$ & \\
\hline \multicolumn{5}{|l|}{$\operatorname{DNR}^{d}(\%)$} \\
\hline No & $83,708(84.5)$ & $8,000(85.6)$ & $75,708(84.3)$ & .0018 \\
\hline Yes & $15,369(15.5)$ & $1,346(13.9)$ & $14,023(15.6)$ & \\
\hline \multicolumn{5}{|l|}{ Cancer subtype (\%) } \\
\hline Lung & $15,055(15.2)$ & $1,301(13.9)$ & $13,754(15.3)$ & $<.0001$ \\
\hline Breast & $9,105(9.2)$ & $451(4.8)$ & $8,654(9.6)$ & \\
\hline Colorectal & $10,068(10.2)$ & $1,223(13.1)$ & $8,845(9.9)$ & \\
\hline Genitourinary & $10,297(10.4)$ & $738(7.9)$ & $9,559(10.7)$ & \\
\hline Other cancer or $>1$ cancer subtype & $28,732(29.0)$ & $3,412(36.5)$ & $25,320(28.2)$ & \\
\hline No identified subtype & $25,828(26.1)$ & $2,223(23.8)$ & $23,605(26.3)$ & \\
\hline \multicolumn{5}{|l|}{ Elective admission ${ }^{\mathrm{e}}(\%)$} \\
\hline No & $75,607(76.3)$ & $7,622(81.5)$ & $67,985(75.8)$ & $<.0001$ \\
\hline Yes & $23,445(23.7)$ & $1,725(18.5)$ & $21,720(24.2)$ & \\
\hline Comorbidity score, mean (SD) & $1.2(1.8)$ & $1.9(1.9)$ & $1.1(1.8)$ & $<.0001$ \\
\hline \multicolumn{5}{|l|}{ Principal diagnosis (\%) } \\
\hline Cancer-related & $50,040(50.5)$ & $4,185(44.8)$ & $45,855(51.1)$ & $<.0001$ \\
\hline Infections & $11,350(11.5)$ & $1,833(19.6)$ & $9,517(10.6)$ & \\
\hline Other pulmonary disorders & $4,888(4.9)$ & $876(9.4)$ & $4,012(4.5)$ & \\
\hline Other cardiovascular and circulation disorders & $5,173(5.2)$ & $340(3.6)$ & $4,833(5.4)$ & \\
\hline Other neurological disorders & $3,229(3.3)$ & $137(1.5)$ & $3,092(3.5)$ & \\
\hline Other GI disorders & $7,989(8.1)$ & $922(9.9)$ & $7,067(7.9)$ & \\
\hline Fluid and electrolyte/renal disorders & $4,178(4.2)$ & $368(3.9)$ & $3,810(4.3)$ & \\
\hline Others & $12,238(12.4)$ & $687(7.4)$ & $11,551(12.9)$ & \\
\hline Teaching hospital ${ }^{f}(\%)$ & $48,885(49.8)$ & $4345(50.1)$ & $44,540(50.1)$ & $<.0001$ \\
\hline Urban $^{f}(\%)$ & $96,674(98.6)$ & $9155(98.5)$ & $87,519(98.5)$ & .0001 \\
\hline \multicolumn{5}{|l|}{ Bed size ${ }^{g}(\%)$} \\
\hline Small $(<200)$ & $24,338(24.8)$ & $2463(26.6)$ & $21,875(24.6)$ & $<.0001$ \\
\hline Medium (200-399) & $44,057(44.9)$ & 3975 (43.0) & $40,082(45.1)$ & \\
\hline Large $(\geq 400)$ & $29,682(30.3)$ & $2808(30.4)$ & $26,874(30.2)$ & \\
\hline
\end{tabular}

Abbreviations: CCTs, critical care therapies; DNR, do not resuscitate; GI, gastrointestinal.

a297 missing.

b3,274 missing

c4 missing.

d8 missing.

e33 missing.

f1,008 missing.

2,411 missing.

with lung cancer (OR, 1.85; 95\% CI, 1.43-2.27). Insurance status and ESRD were not predictors of CCTs in the DNR group.
When we limited the examination to IMV use, non-white races and greater comorbidity burden were significant predictors of IMV use in both groups with 
Loh et al

\begin{tabular}{|c|c|c|c|c|}
\hline Characteristics & $\begin{array}{l}\text { All Admissions } \\
(n=99,085)\end{array}$ & $\begin{array}{l}\text { Received CCTs } \\
(n=9,348)\end{array}$ & $\begin{array}{l}\text { Did Not Receive CCTs } \\
(n=89,737)\end{array}$ & $P$ Value \\
\hline \multicolumn{5}{|l|}{ Discharge disposition ${ }^{\mathrm{a}}$} \\
\hline Home & $52,798(59.2)$ & $1,990(31.7)$ & $50,808(61.3)$ & $<.0001$ \\
\hline Short-term hospital & $2,426(2.7)$ & $383(6.1)$ & $2,043(2.5)$ & \\
\hline SNF, ICF, facility & $13,188(14.8)$ & $1,627(25.9)$ & $11,561(14.0)$ & \\
\hline Home health care & $18,761(21.1)$ & $2,110(33.6)$ & $16,651(20.1)$ & \\
\hline AMA & $547(0.6)$ & $27(0.4)$ & $520(0.6)$ & \\
\hline Discharge alive, unknown & $1,415(1.6)$ & $149(2.4)$ & $1,266(1.5)$ & \\
\hline \multicolumn{5}{|l|}{ Total $\cos \mathrm{t}^{\mathrm{b}}$} \\
\hline Median (IQR) & $12,858(7,071-23,842)$ & $35,422(18,978-63,403)$ & $11,860(6,707-21,087)$ & $<.0001$ \\
\hline \multicolumn{5}{|l|}{ Length of stay, $\mathrm{d}^{\mathrm{c}}$} \\
\hline Mean (SD) & $6.8(9.2)$ & $14.8(15.6)$ & $5.9(7.8)$ & $<.0001$ \\
\hline In-hospital mortalitya & $9,944(10.0)$ & $3,046(33.3)$ & $6,884(7.7)$ & $<.0001$ \\
\hline
\end{tabular}

Abbreviations: AMA, against medical advice; CCTs, critical care therapies; ICF, intermediate care facilities; IQR, interquartile range; SNF, skilled nursing facilities.

aPatients who survived the hospitalizations; denominator $=89,135 ; 6$ missing.

bBased on cost/charge ratio; 15,626 missing.

'15 missing.

or without DNR orders (Table 4). Among patients who did not have a DNR order, those with weight loss (OR, 1.83; 95\% CI, 1.69-1.98) and liver diseases (OR, 1.33; 95\% CI, 1.14-1.52) were more likely to receive IMV, whereas patients with ESRD were less likely to receive IMV (OR, 0.77; 95\% CI, 0.56-0.97). None of these comorbidities were predictors of IMV use in the group with DNR orders. Younger patients (aged $<55$ years) were more likely than older patients ( $\geq 75$ years) to receive IMV among those who had DNR orders. Similar to the use of CCTs, among patients who were not DNR, those who had breast and GU cancers were less likely to receive IMV compared with those with lung cancer, but these associations were not statistically significant in the group with DNR orders (and, in fact, the direction of the OR for breast cancer was switched in the DNR group).

\section{Discussion}

Using data from the CA SID we found that, not surprisingly, patients with metastatic cancer who received CCTs had much worse outcomes than those who did not, including a 4 times greater rate of in-hospital death, 3 times longer hospital stays, and 3 times higher costs of care. More importantly, we identified that CCT use varied across several patient and clinical characteristics, which may help clinicians as they assess the likelihood that a patient with metastatic cancer may require CCTs when being admitted to the hospital.
A number of predictors found in our study are important for clinical practice. Patients of nonwhite race with DNR orders were more likely to receive CCTs. Non-white race was also associated with IMV use in patients with and without DNR orders. This may be due to the fact that patients of nonwhite race are less likely to have DNR orders and more likely to have a preference for life-prolonging care. ${ }^{23-25}$ Non-white patients are also more likely to change their DNR orders during hospitalization to a more aggressive level of care. ${ }^{26}$ Among patients with DNR orders, those who were older had lower odds of receiving CCTs compared with younger patients, reflecting the fact that younger patients were more likely to have their DNR orders changed while hospitalized. Age was not a predictor of IMV use in patients without DNR orders.

Not surprisingly, patients with or without DNR orders who had a higher burden of comorbidities were more likely to receive CCTs, indicating their underlying severity of illness. Despite having DNR orders, it is interesting that patients with a higher burden of comorbidities were still more likely to receive IMV, indicating that the goals-of-care discussion is an ongoing discussion in the hospital. Nevertheless, physicians should be mindful that a high comorbidity burden is still associated with a high rate of in-hospital deaths. ${ }^{12}$ Weight loss was associated with greater CCT use in patients with or without DNR orders and greater IMV use in patients 
Critical Care Therapies in Cancer

\begin{tabular}{|c|c|c|}
\hline \multirow[b]{2}{*}{ Variables } & \multicolumn{2}{|c|}{$\begin{array}{c}\text { CCT Use } \\
\text { Adjusted Odd Ratios }(95 \% \mathrm{Cl})\end{array}$} \\
\hline & $\begin{array}{c}\text { No DNR } \\
(n=15,369)\end{array}$ & $\begin{array}{c}\text { DNR } \\
(n=83,708)\end{array}$ \\
\hline \multicolumn{3}{|l|}{ Age, y } \\
\hline$<55$ & 1 (referent) & 1 (referent) \\
\hline $55-64$ & $1.09(1.02-1.17)$ & $0.89(0.72-1.06)$ \\
\hline $65-74$ & $1.12(1.02-1.22)$ & $0.86(0.67-1.06)$ \\
\hline$\geq 75$ & $0.98(0.89-1.07)$ & $0.62(0.48-0.76)$ \\
\hline \multicolumn{3}{|l|}{ Sex } \\
\hline Male & 1 (referent) & 1 (referent) \\
\hline Female & $0.95(0.90-1.00)$ & $1.01(0.89-1.14)$ \\
\hline \multicolumn{3}{|l|}{ Race } \\
\hline White & 1 (referent) & 1 (referent) \\
\hline Hispanic & $0.96(0.89-1.03)$ & $1.08(0.89-1.27)$ \\
\hline Black & $1.07(0.98-1.15)$ & $1.31(1.08-1.54)$ \\
\hline Other & $1.07(0.97-1.17)$ & $1.41(1.09-1.72)$ \\
\hline \multicolumn{3}{|l|}{ Payer } \\
\hline Medicare & 1 (referent) & 1 (referent) \\
\hline Medicaid & $1.07(0.97-1.17)$ & $0.95(0.73-1.18)$ \\
\hline Private insurance & $1.14(1.05-1.23)$ & $1.16(0.95-1.37)$ \\
\hline No charge/other & $1.07(0.83-1.30)$ & $0.79(0.33-1.26)$ \\
\hline Self-pay & $0.93(0.75-1.11)$ & $1.23(0.65-1.81)$ \\
\hline \multicolumn{3}{|l|}{ Elective admission } \\
\hline Yes & $0.97(0.91-1.04)$ & $1.17(0.90-1.44)$ \\
\hline \multicolumn{3}{|l|}{ Comorbidity score } \\
\hline$\leq 0$ & 1 (referent) & 1 (referent) \\
\hline 1 & $1.70(1.59-1.82)$ & $1.33(1.11-1.55)$ \\
\hline$\geq 2$ & $2.51(2.36-2.67)$ & $1.56(1.33-1.80)$ \\
\hline \multicolumn{3}{|l|}{ Comorbidities } \\
\hline Weight loss & $3.23(3.04-3.42)$ & $2.23(1.94-2.52)$ \\
\hline ESRD & $0.55(0.41-0.68)$ & $0.82(0.43-1.20)$ \\
\hline Liver diseases & $1.00(0.89-1.12)$ & $0.85(0.64-1.07)$ \\
\hline \multicolumn{3}{|l|}{ Cancer subtype } \\
\hline Lung & 1 (referent) & 1 (referent) \\
\hline Breast & $0.71(0.62-0.80)$ & $1.11(0.81-1.41)$ \\
\hline Colorectal & $1.67(1.51-1.83)$ & $1.85(1.43-2.27)$ \\
\hline Genitourinary & $0.89(0.79-0.99)$ & $0.98(0.74-1.22)$ \\
\hline Other cancer or $>2$ subtypes & $1.64(1.51-1.77)$ & $1.52(1.26-1.78)$ \\
\hline No identified cancer subtype & $1.11(1.02-1.20)$ & $1.40(1.15-1.65)$ \\
\hline \multicolumn{3}{|l|}{ Principal diagnosis } \\
\hline Cancer-related & 1 (referent) & 1 (referent) \\
\hline Infections & $1.62(1.50-1.74)$ & $1.87(1.59-2.16)$ \\
\hline Other pulmonary disorders & $2.03(1.83-2.23)$ & $2.57(2.07-3.07)$ \\
\hline Other cardiovascular and circulation disorders & $0.67(0.58-0.76)$ & $1.11(0.82-1.41)$ \\
\hline Other neurologic and psychiatric disorders & $0.53(0.43-0.63)$ & $0.40(0.22-0.58)$ \\
\hline Other GI disorders & $1.20(1.10-1.31)$ & $1.36(1.07-1.66)$ \\
\hline Fluid and electrolyte/renal disorders & $0.99(0.87-1.12)$ & $0.84(0.59-1.09)$ \\
\hline Others & $0.64(0.58-0.70)$ & $0.67(0.51-0.83)$ \\
\hline
\end{tabular}

Abbreviations: CCT, critical care therapy; DNR, do-not-resuscitate status; ESRD, end-stage renal disease; GI, gastrointestinal. 
Loh et al

\begin{tabular}{|c|c|c|}
\hline \multirow[b]{2}{*}{ Variables } & \multicolumn{2}{|c|}{$\begin{array}{c}\text { IMV Use } \\
\text { Adjusted Odd Ratios }(95 \% \mathrm{Cl})\end{array}$} \\
\hline & $\begin{array}{c}\text { DNR } \\
(n=15,369)\end{array}$ & $\begin{array}{c}\text { No DNR } \\
(\mathrm{n}=83,708)\end{array}$ \\
\hline \multicolumn{3}{|l|}{ Age, y } \\
\hline$<55$ & 1 (referent) & 1 (referent) \\
\hline $55-64$ & $1.02(0.92-1.13)$ & $0.84(0.62-1.05)$ \\
\hline $65-74$ & $1.12(0.98-1.26)$ & $0.86(0.61-1.11)$ \\
\hline$\geq 75$ & $0.93(0.81-1.06)$ & $0.56(0.39-0.73)$ \\
\hline \multicolumn{3}{|l|}{ Sex } \\
\hline Male & 1 (referent) & 1 (referent) \\
\hline Female & $0.94(0.87-1.00)$ & $0.91(0.76-1.06)$ \\
\hline \multicolumn{3}{|l|}{ Race } \\
\hline White & 1 (referent) & 1 (referent) \\
\hline Hispanic & $1.04(0.94-1.14)$ & $1.52(1.18-1.87)$ \\
\hline Black & $1.18(1.05-1.30)$ & $1.59(1.23-1.95)$ \\
\hline Other & $1.25(1.10-1.39)$ & $1.95(1.42-2.49)$ \\
\hline \multicolumn{3}{|l|}{ Payer } \\
\hline Medicare & 1 (referent) & 1 (referent) \\
\hline Medicaid & $1.12(0.98-1.26)$ & $0.98(0.68-1.28)$ \\
\hline Private insurance & $1.08(0.96-1.20)$ & $1.08(0.82-1.34)$ \\
\hline No charge/other & $1.35(0.96-1.74)$ & $1.17(0.38-1.96)$ \\
\hline Self-pay & $1.02(0.74-1.29)$ & $1.78(0.83-2.75)$ \\
\hline \multicolumn{3}{|l|}{ Elective admission } \\
\hline Yes & $1.08(0.97-1.18)$ & $1.27(0.88-1.65)$ \\
\hline \multicolumn{3}{|l|}{ Comorbidity score } \\
\hline$\leq 0$ & 1 (referent) & 1 (referent) \\
\hline 1 & $2.25(2.01-2.50)$ & $1.41(1.09-1.74)$ \\
\hline$\geq 2$ & $3.81(3.43-4.19)$ & $1.76(1.40-2.12)$ \\
\hline \multicolumn{3}{|l|}{ Comorbidities } \\
\hline Weight loss & $1.83(1.69-1.98)$ & $1.17(0.95-1.39)$ \\
\hline ESRD & $0.77(0.56-0.97)$ & $1.19(0.55-1.82)$ \\
\hline Liver diseases & $1.33(1.14-1.52)$ & $1.00(0.67-1.32)$ \\
\hline \multicolumn{3}{|l|}{ Cancer subtype } \\
\hline Lung & 1 (referent) & 1 (referent) \\
\hline Breast & $0.75(0.63-0.87)$ & $1.00(0.65-1.34)$ \\
\hline Colorectal & $0.94(0.81-1.06)$ & $1.05(0.70-1.39)$ \\
\hline Genitourinary & $0.71(0.61-0.80)$ & $0.75(0.51-0.99)$ \\
\hline Other cancer or $>2$ subtypes & $0.97(0.87-1.07)$ & $1.04(0.81-1.27)$ \\
\hline No identified cancer subtype & $0.86(0.77-0.95)$ & $1.15(0.90-1.41)$ \\
\hline \multicolumn{3}{|l|}{ Principal diagnosis } \\
\hline Cancer-related & 1 (referent) & 1 (referent) \\
\hline Infections & $2.97(2.69-3.24)$ & $3.18(2.52-3.83)$ \\
\hline Other pulmonary disorders & $3.89(3.45-4.34)$ & $5.13(3.91-6.35)$ \\
\hline Other cardiovascular and circulation disorders & $1.09(0.91-1.26)$ & $1.66(1.10-2.22)$ \\
\hline Other neurologic and psychiatric disorders & $0.72(0.54-0.91)$ & $0.60(0.25-0.95)$ \\
\hline Other GI disorders & $0.59(0.49-0.70)$ & $0.84(0.50-1.17)$ \\
\hline Fluid and electrolyte/renal disorders & $0.34(0.25-0.45)$ & $0.16(0.01-0.31)$ \\
\hline Others & $0.60(0.52-0.69)$ & $0.67(0.42-0.91)$ \\
\hline
\end{tabular}

Abbreviations: DNR, do-not-resuscitate status; ESRD, end-stage renal disease; GI, gastrointestinal; IMV, invasive mechanical ventilation.

(C) JNCCN_Journal of the National Comprehensive Cancer Network | Volume 15 Number 1 | January 2017 
without DNR orders. This finding supports prior studies showing weight loss as a prognostic indicator and reinforces the importance of asking all admitted patients with metastatic cancer about recent (and profound) weight loss, which can help clinicians to identify and address a group of patients at high risk for CCT use. ${ }^{27,28}$ Liver disease was associated with a higher likelihood of IMV use in the group without DNR orders. Intervention, such as a goals-of-care discussion, could be potentially targeted to this group of patients who also have a higher risk of in-hospital mortality (shown in our prior study ${ }^{12}$ : OR, 1.58; $95 \%$ CI, 1.15-2.00). The higher in-hospital mortality rate in patients with cancer with hepatic failure was also shown in a study by Kress et al. ${ }^{29}$

One notable comorbidity that did not increase the use of CCTs was ESRD; in fact, patients with ESRD without DNR orders were less likely to receive CCTs. This is also an important finding because patients with ESRD and metastatic cancer are clearly among those at the highest risk for CCT use and death. It raised the question of why CCT was used less in this group. We suspect that clinicians, families, and patients are able to recognize the high risk of morbidity and mortality in this group and opt for a less aggressive approach in the setting of an acute illness (17\% of patients with ESRD had an encounter with palliative care, based on ICD-9-CM diagnosis code V66.7). This finding is somewhat encouraging, because it may indicate that when it is clear that the prognosis is not good, patients, families and clinicians opt to forgo CCTs (eg, changing code status, opting for hospice care, or choosing a do-not-hospitalize approach). This may not have been captured in the database, because the DNR orders were recorded within 24 hours of admission. This is supported by prior studies showing that advance directives were present only in $6 \%$ to $35 \%$ of patients on chronic dialysis. ${ }^{30}$ When these patients were admitted, $45 \%$ had their care changed from disease-directed to symptom-directed in the hospital and 34\% had a palliative care team involved. ${ }^{31}$

Our data suggest that oncologists and internists can approach the management of patients with a high number of comorbidities or, specifically, end-stage liver disease in a similarly cautious way. Patients admitted with infections or pulmonary disorders were 4 times more likely to receive
IMV. An admission for a patient with metastatic cancer and a new infection or a pulmonary diagnosis with or without DNR orders should be considered at high-risk for CCT use. Potential interventions, such as early initiation of close monitoring, need to be studied in this at-risk population. Additionally, discussion of risks and benefits of invasive treatment along with goals-of-care discussions should be prioritized.

We made some observations when we analyzed cancer subtypes and the use of CCTs. Within the group without a DNR order, patients with lung cancer had a higher likelihood of receiving CCTs and IMV compared with those with breast and GU cancers. These differences were attenuated in the DNR group. Patients with CRC had a higher likelihood of receiving CCTs than those with lung cancer. We attributed these findings to the fact that patients with lung cancer are usually sicker, with frequent presence of underlying primary lung disease. The higher use of TPN likely explained the high rate of CCT use in patients with CRC. Although selection bias or inherent risk may factor into decision-making, knowing the risk of receiving CCTs for patients with varying cancer types stratified by DNR status offers important information for clinicians as they help patients and families make treatment decisions.

Given that all the variables collected in our study are accessible through most electronic health records (EHRs), creating EHR tools to help clinicians during the admitting process could help identify the highest risk patients in real time. Having this information will help clinicians develop strategies to avoid CCT use in patients unlikely to benefit. On the other hand, for patients who may benefit from CCTs, strategies such as more intensive monitoring or early transfer to the intensive care unit can be considered. However, these strategies need to be studied further before they are adopted in clinical practice.

Our study is limited by its retrospective nature. Because there are clearly selection issues (some patients were not eligible to receive CCTs because of patient, family, or physician decision-making), our findings need to be interpreted carefully and should not be considered an examination of the effectiveness of CCTs. We used a large administrative database, which lacked clinical information such as laboratory data or vital signs. Similarly, we therefore 
lacked the ability to identify severity of illness at admission. Given that we evaluated the use of CCTs, it is very likely that the presenting severity played an important role that we were unable to assess. Definitions of metastatic cancer are based on ICD-9 codes that have not been validated. Additionally, we were not able to retrieve information related to cancer severity and treatments.

\section{Conclusions}

Patient characteristics, such as non-white race, higher burden of comorbidities, weight loss, liver disease, lung cancer subtype, and diagnosis of infections or pulmonary disorders, were associated with higher odds of receiving CCTs or IMV. These findings may help clinicians admitting these patients (especially those without DNR orders) to determine in whom to prioritize discussions around goals of care and wishes for the end of life.

\section{References}

1. Mariotto AB, Yabroff KR, Shao Y, et al. Projections of the cost of cancer care in the United States: 2010-2020. J Natl Cancer Inst 2011;103:117128.

2. Yabroff KR, Lamont EB, Mariotto A, et al. Cost of care for elderly cancer patients in the United States. J Natl Cancer Inst 2008;100:630-641.

3. O'Neill CB, Atoria CL, O'Reilly EM, et al. ReCAP: hospitalizations in older adults with advanced cancer: the role of chemotherapy. J Oncol Pract Am Soc Clin Oncol 2016;12:151-152.

4. Earle CC, Landrum MB, Souza JM, et al. Aggressiveness of cancer care near the end of life: is it a quality-of-care issue? J Clin Oncol 2008;26:3860 3866.

5. Zilberberg MD, Shorr AF. Economics at the end of life: hospital and ICU perspectives. Semin Respir Crit Care Med 2012;33:362-369.

6. Brooks GA, Kansagra AJ, Rao SR, et al. A clinical prediction model to assess risk for chemotherapy-related hospitalization in patients initiating palliative chemotherapy. JAMA Oncol 2015;1:441-447.

7. Gorham J, Ameye L, Paesmans M, et al. The Glasgow inflammatory score and lung cancer: a predictor of admissions to emergency units [in French]. Rev Mal Respir 2016;33:759-765.

8. Rocque GB, Barnett AE, Illig LC, et al. Inpatient hospitalization of oncology patients: are we missing an opportunity for end-of-life care? J Oncol Pract Am Soc Clin Oncol 2013;9:51-54.

9. Paris J, Morrison RS. Evaluating the effects of inpatient palliative care consultations on subsequent hospice use and place of death in patients with advanced GI cancers. J Oncol Pract Am Soc Clin Oncol 2014;10:174-177.

10. Nurgalieva Z, Liu CC, Du XL. Risk of hospitalizations associated with adverse effects of chemotherapy in a large community-based cohort of elderly women with ovarian cancer. Int J Gynecol Cancer Off J Int Gynecol Cancer Soc 2009;19:1314-1321.

11. Prince RM, Atenafu EG, Krzyzanowska MK. Hospitalizations during systemic therapy for metastatic lung cancer: a systematic review of real world vs clinical trial outcomes. JAMA Oncol 2015;1:1333-1339.

12. Loh KP, Kansagra A, Shieh MS, et al. Predictors of in-hospital mortality in patients with metastatic cancer who are receiving specific critical care therapies. J Natl Compr Canc Netw 2016;14:979-987.

13. Weiner MG, Livshits A, Carozzoni C, et al. Derivation of malignancy status from ICD-9 codes. AMIA Annu Symp Proc 2003;2003:1050.

14. Eichler AF, Lamont EB. Utility of administrative claims data for the study of brain metastases: a validation study. J Neurooncol 2009;95:427-431.

15. Dolan MT, Kim S, Shao YH, et al. Authentication of algorithm to detect metastases in men with prostate cancer using ICD-9 codes. Epidemiol Res Int 2012;2012:e970406.

16. Elixhauser A, Steiner C, Harris DR, Coffey RM. Comorbidity measures for use with administrative data. Med Care 1998;36:8-27.
17. Gagne JJ, Glynn RJ, Avorn J, et al. A combined comorbidity score predicted mortality in elderly patients better than existing scores. J Clin Epidemiol 2011;64:749-759.

18. Goldman LE, Chu PW, Osmond D, Bindman A. Accuracy of do not resuscitate (DNR) in administrative data. Med Care Res Rev 2013;70:98112.

19. Goldman LE, Chu PW, Prothro C, et al eds. Accuracy of condition present on admission, do not resuscitate, and e-codes in California Patient Discharge Data. Available at: http://www.oshpd.ca.gov/HID/Products/ PatDischargeData/ResearchReports/PDDValidation/PDD_Validation_ Study.pdf. Accessed July 16, 2016.

20. Clinical Classifications Software (CCS) for ICD-9-CM. Healthcare Cost and Utilization Project Web site. http://www.hcup-us.ahrq.gov/ toolssoftware/ccs/ccs.jsp. Accessed Sept 19, 2015

21. American Hospital Association. The AHA Annual Survey Database Fiscal Year 2014. Chicago, IL: American Hospital Association; 2015.

22. Cost-to-Charge Ratio Files. Healthcare Cost and Utilization Project Web site. Available at http://www.hcup-us.ahrq.gov/db/state/costtocharge.jsp. Accessed September 19, 2015.

23. Suga JM, Nguyen DV, Mohammed SM, et al. Racial disparities on the use of invasive and noninvasive staging in patients with non-small cell lung cancer. J Thorac Oncol 2010;5:1772-1778.

24. Shavers VL, Brown ML. Racial and ethnic disparities in the receipt of cancer treatment. J Natl Cancer Inst 2002;94:334-357.

25. Simpson DR, Martínez ME, Gupta S, et al. Racial disparity in consultation, treatment, and the impact on survival in metastatic colorectal cancer. J Natl Cancer Inst 2013;105:1814-1820.

26. Garrido MM, Harrington ST, Prigerson HG. End-of-life treatment preferences: a key to reducing ethnic/racial disparities in advance care planning? Cancer 2014;120:3981-3986.

27. Walter V, Jansen L, Hoffmeister M, et al. Prognostic relevance of prediagnostic weight loss and overweight at diagnosis in patients with colorectal cancer. Am J Clin Nutr 2016;104:1110-1120.

28. Lin J, Peng J, Qdaisat A, et al. Severe weight loss during preoperative chemoradiotherapy compromises survival outcome for patients with locally advanced rectal cancer. J Cancer Res Clin Oncol 2016;142:2551-2560.

29. Kress JP, Christenson J, Pohlman AS, et al. Outcomes of critically ill cancer patients in a university hospital setting. Am J Respir Crit Care Med 1999;160:1957-1961.

30. Holley JL, Nespor S, Rault R. The effects of providing chronic hemodialysis patients written material on advance directives. Am J Kidney Dis 1993;22:413-418.

31. McAdoo SP, Brown EA, Chesser AM, et al. Measuring the quality of end of life management in patients with advanced kidney disease: results from the pan-Thames renal audit group. Nephrol Dial Transplant 2012;27:15481554 . 